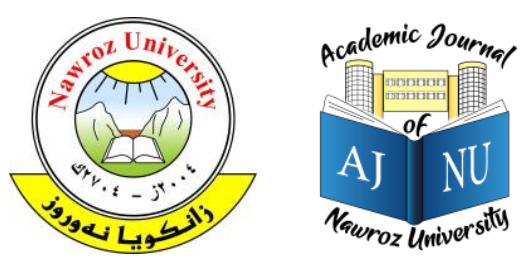

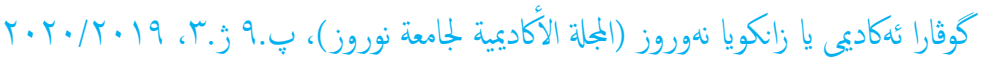

حقوق الطبع والنشر (2017. هذه مقالة الوصول اليها مفتوح موزعة تحت رخصة

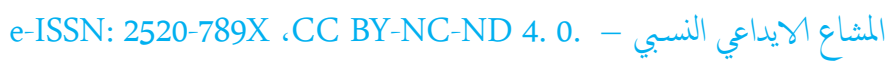

https://doi.org/10.25007/ajnu.v9n3a841

\title{
دور التخطيط الاستراتيجي للتسويق في تعزيز الأداء التسويتي/دراسة استطلاعية لاراء عينة من الموظفين في عدد من مصارف مدينة دهوك
}

ثئهين سليم نوري، قسم تقنية المعلومات، المعهد التقني(زائر في جامعة نوروز)، دهوك، إقليم كوردستان- العراق

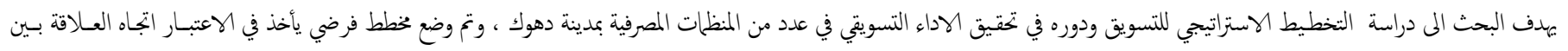

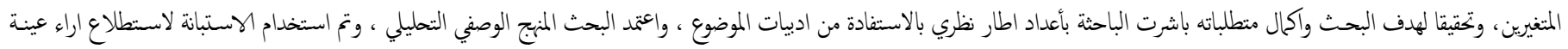

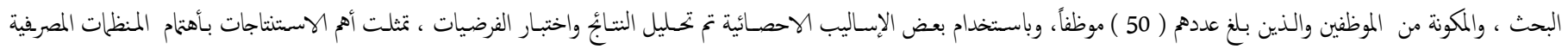

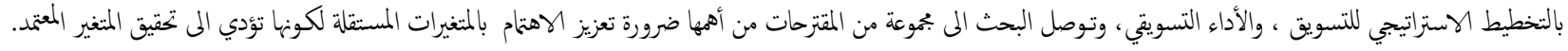

الكلمات المفتاحية: التخطيط الاستراتيجي التسويق، الاداء التسويقي.

1. المقدمة

مراقبة تقدم التسويق نحو أهدافه السنوية، وتحديد مجالات المزيج التسويقي التي تحتاج إلى تعديل أو تحسين لزيادة بعض جوانب الأداء، فضلا عن تقييم ما إذا كانت سلع الشركة وخدماتها وأفكارها تلبي احتياجات الزبائن وأصحاب المصلحة.

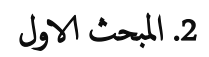
1.2

1.1.2 مشكلة البحث

لقد اصبح عملية التخطيط الاستراتيجي للتسويق أمراً في غاية الاهمية لمنظلات الاعحال وخصوصاً التي تسعى الى تحقيق البقاء والنمو والنجاح، وتنبع أهمية التخطيط التسويقي من أهمية التسويق الاستراتيجي على جميع مستويات المنظمة إذ تعتبر الخطة التسويقية للمنظمة بمثابة الترقيم والحيوية للأهداف، وأظهر العديد من الدراسات ان المنظلات التي تعتمد التخطيط الاسترانيجي للتسويق قد حققت فرصاً أكبر للنجاح ،ان مسؤولو التسويق في المصارف يتخذون قرارات تخص منتجاتهم المصرفية على المستويين الاستراتيجي والتنفيذي ،لذلك فان فهم ودراسة البيئة التسويقية يساعد المسؤولين في اتخاذ القرارات الدقيقة والتي من الممكن ان تساعد المصارف في تعزيز أدائها التسويقي ، استنادا الى ذلك ميكن توضيح مشكلة

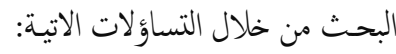

تهدف المنظات من إستخدام التخطيط الاستراتيجي للتسويق الى تحديد وخلق الميزة التنافسية، ويتضمن ايضاً سلسلة من الاستراتيجيات التسويقية والتكتيكات. وتجري عملية التخطيط الاستراتيجي للتسويق على عدة مستويات تنظيمية كلمستويات التنظيمة العالية، وعلى مستوى وحدة الأعال، فضلاً عن المستوى الوظيفي، فالتخطيط الاستراتيجي اللتسويق على المستويات العليا يتضمن تحديد المهمة، والأهداف، وإنشاء وحدات الأعحال الاستراتيجية وتظيم الأنشطة من أجل القضاء على نقاط الضعف للفترة الحالية أهدافها. أما التخطيط الاسترانيجي للتسويق على مستوى وحدة الاعمال، فتتضمن تحديد واستغلال ميزة الأعال الاستراتيجية تحديد المهمة، وتحليل نقاط القوة والضفف والفرص والأخطار على البيئة الداخلية والخارجية للشركة، وصياغة الأهداف، ووضع الاستراتيجية، ووضع برنامج التسويق، والتنفيذ، والتغذية العكسية الخ، ويتضمن التخطيط الاستراتيجي للتسويق على مستوى الوظائف تحديد استراتيجيات للوظيفة المالية والإنتاج والافراد وغيرها. يعد الأداء التسويقي أحد المؤشرات المهمة لقياس مدى تأثير أنشطة التسويق والإنفاق على صافي أرباح المنظمة، وهذا شيء همم لأن المنظمات تميل إلى تقليل ميزانيات التسويق خلال فترات الانكماش الاقتصادي، ويساهم قياس الأداء الى 
- - ـ يسعى البحث المى توظيف الإطار النظري للاستفادة من المعلومات التي يمكن الحصول عليها والتي تخدم في تحسين الاداء التسويقي.

- - التوصل الى أهم الاستناجات والتوصيات من خلال دراسة واقع المنظلات المبحوثة عن طريق تبني والاعتاد على التخطيط الاستراتيجي للتسويق

$$
\begin{aligned}
& \text { ودورها في الاداء التسويتي. } \\
& \text { إنموذج البحث }
\end{aligned}
$$

تمهيداً لصياغة فرضيات البحث الرئيسة والفرعية فقد تم بناء خخطط افتراضي يصنف

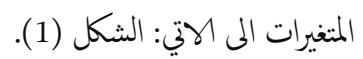

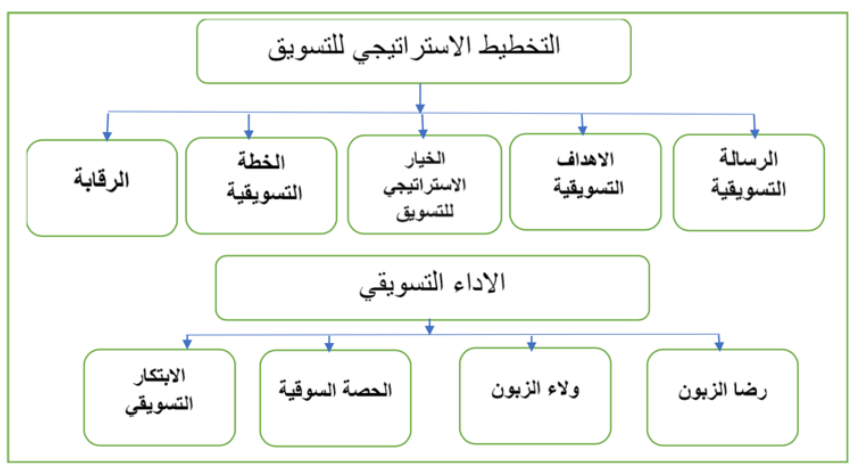

الشكل 1. إنموذج البحث

5.1.2 فرضيات البحث

توجد علاقة ارتباط معنوية بين ابعاد التخطيط الاستراتيجي اللتسويق مجتمة

$$
\text { وابعاد الاداء التسويقي مجتمعة. }
$$

توجد علاقة ارتباط معنوية بين ابعاد التخطيط الاستراتيجي للتسويق منفردة

$$
\text { والاداء التسويقي مجتمعة. }
$$

يوجد تأثثر معنوي موجب لأبعاد التخطيط الاستراتيجي للتسويق مجتمة في

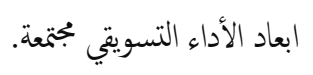

يوجد تأثثر معنوي موجب لأبعاد التخطيط الاستراتيجي اللتسويق منفردة في

$$
\begin{gathered}
6.1 .2 \\
\text { الأساليب الأداء التسويقي مجتمعة. }
\end{gathered}
$$

ما مستوى تطبيق المصارف الحكومية في مدينة دهوك للتخطيط

$$
\text { الاستراتيجي للتسويق؟ }
$$

ما مستوى الاداء التسويتي في المصارف الحكومية في مدينة دهوك ؟ هل للتخطيط الاستراتيجي للتسويق بعناصره مجتمعة دور في تعزيز الأداء

$$
\text { التسويقي في المصارف الحكومية . }
$$

هل توجد علاقةً ارتباط معنوية بين التخطيط الاستراتيجي للتسويق والاداء

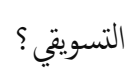

هل يؤثر التخطيط الاستراتيجي التسويق في الأداء التسويقي؟

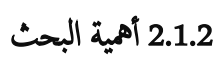

ثكمن أهمية البحث في كونها محاولة لتسليط الضوء على مجموعة من المتغيرات المترابطة فيـا بينها، حيث تبدأ بالتخطيط الاستراتيجي اللتسويق وتنهي بدراسة الاداء التسويقي للمصارف وبيان أثركل متغير من هذه المتغيرات على المصارف في اطار سعيها لتحقيق اهدافها مع توضيع العلاقة التي يكن أن تظهر بين هذا النوع من التخطيط والأداء نظراً للتحولات التي رافقت المصارف من خلال انضماهما الى لى

$$
\text { المصارف الهملية والعالمية. }
$$

$$
\text { وعليه تتمثل أهمية البحث بآلاتي: }
$$

إعطاء فكرة عن الإطار النظري عن متغري النخطيط الاستراتبجي للتسويق

$$
\text { والاداء التسويقي. }
$$

يتناول البحث قطاعا حيويا يتمثل بعدد من المصارف الحكومية في مدينة دهوك ،والتي تعد من الركايز الأساسية لاقتصاد الأقليم.

يستمد أهميته من النتائُ المتوقعة منه، والتي من الممكن ان تساهم على تقديم دليل علمي وعملي عن واقع التخطيط الاستراتيجي للتسويق في المصارف

$$
\text { الحكومية . }
$$

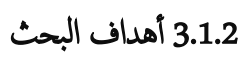

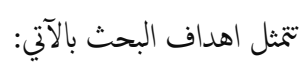

- - تفعيل الدور التخطيط الاستراتيجي للتسويق في المنظلات المبحوثة. 


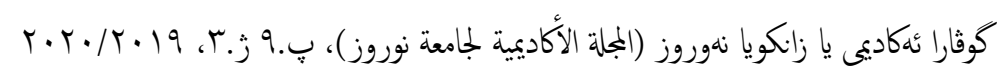

أدى تزايد الوعي باهية التسويق كفلسفة ومنهاج عمل في معظم المنظات الحديثة الى تبني مفهوم التخطيط الاستراتيجي للتسويق لمعظم أنشطة وفعاليات إدارة التسويق، لكونه أسلوب علمي متكامل يري إلى تحقيق الأهداف الموضوعية بشكل مقبول لكل من طرفي المعادلة، المنتج والمستهلك معاً ومن خلال وضع تشريعات تمنع الاحتكار وتصون حقوق المستهاك (حلو، 2013: 166). يمثل التخطيط الاسترانيجي للتسويق نشاط إداري مرتبط بعملية تحديد الاهداف الرئيسية لمنظات الاعمال التي تسعى الى تحقيق وتحديد أدوات التصرف البديلة التي يمكن من خلالها الوصول المى الاهداف الحمددة بأقل التكليف وأفضل الطرق، وعملية التخطيط التسويقي تأخذ بعد إستراتيجي عندما تكون الموارد والامكانيات المتاحة محددة لدى الادارة، إذ تكمن همة المنظمة في تعظيم العوائد والارباح من اجل تبني منهجية تسويقية قادرة على التنظيم والتنسيق بين كافة الجهود المبذولة لإنجاح التخطيط التسويقي بابعاده الاستراتيجية إذ يتمد هذا النوع من التخطيط على التفكير المعمق والابداع التسويقي خصوصاً في عالم يسوده بيئة متحركة بشكل سريع مما يتطلب المقدرة على النكيف مع كافة الاوضاع حتى تستطع المنظمة من خلال خططها التسويقية الاستجابة لمتطلبات النجاح والمحافظة على البقاء. عرفها (البكري، 2008: 169) التخطيط الاستراتيجي اللتسويق بانها العملية الادارية الخاصة بوضع وإدامة العلاقة بين أهداف المنظمة والمهارات المتاحة والفرص التسويقية المتغيرة. وورد علن إنه تحديد بمجوعة من الاهداف مع وضع مُموعةُ من الاناليب والاجراءات والتنظيات اللآزمة لتحقيق تلك الاهدافْ بأقل تكلة او بأكبر ربح مككن، كما انه اختيار افضل البدائل التسويقية المتاحة لتحقيق اهداف المنظمة المنشودة (العوامرة والزيادات، 2012: 100). ويعرف بإنه النشاط الاداري المرتبط بعملية تحويل الاهْداف الرئيسية التي تسعى المنظمة الى تحقيقها، وتحديد أساليب التصرف البديلة التي يمكن بواسطنها تحقيق الاهداف بأفضْل الطرق وأقل التكليف وينطوي ذلكِك على عملية عقلانية تستهدف دراسة وتحليل كل هذه الاساليب وتيمها على أساش مدى مساهمتا في تحقيق الاهداف بما يؤدي في النهاية للى إختيار الحسلوب الانسب (الذويب، 2015: من أجل الحصول على البيانات والمعلومات اللازمة لإتمام هذا البحث واختبار فرضياته، وبغية الوصول إلى النتأُج وتحقيق أهداف الدراسة فقد اعتمدت الباحثة على

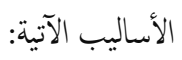
أ. الإطار النظري:بغية تغطية الجانب النظري للدراسة فقد إعتمدت الباحثة على العديد من المصادر المتثلة بالمراجع العلمية من كتب ومجلات ودراسات ورسائل جامعية ذات الصلة بالموضوع للوصول إلى إطار نظري واضح ومنكامل للموضوع. ب. الإطار العملي: اعتمدت على استمارة الاستبيان كوسيلة رئيسة في الحصول على البيانات فيما يتعلق بمتغرات الدراسة والتي كانت الباحثة قد أعدت أسئلنها بالاعتقاد على عدد من الدراسات والأبحاث، وقد تم استخدام مقياس ليكرت المُاسي في استمارة الاستبانة والمرتب من عبارة اتفق بشدة والتي أخذت الوزن (5 صحيح) إلى عبارة لا اتفق بشدة التي أخذت الوزن (1) صهيح). وقد تضمنت الاستبانة بمحوعتين من الاسئلة؛ الأولى تضمنت المعلومات التعريفية التي تخص المجيب، اما المجموعة الثانية من الاستبانة تضمنت الأسئلة الخاصة بالتسويق الاسترانيجي والمجموعة الاخيرة تضمنت الاسئلة الخاصة بالاداء التسويقي. 7.1.2 أساليب التحليل الإحصائي استنادا إلى توجحات وأهداف البحث ومضامين فرضياته استعانت الباحثة بجموعة من الأدوات الإحصائية باستخدام برنامج ( SPSS) وتمثلت هذه الأدوات بالآتي: التكرارات (Frequencies) والنسب المئوية (Percent) والمتوسط الحسابي

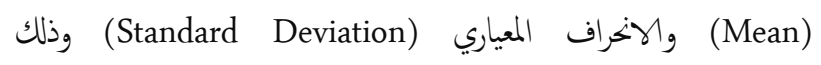

$$
\text { لاستخداها في وصف متغيرات البحث وتشخيصها. }
$$

معامل الارتباط البسيط (Bivariate Correlation): تم استخدامه لتحديد قوة وطبيعة العلاقة الارتباط بين المتغير المستقل والمتغيرات التابعة.

$$
\begin{aligned}
& \text { F, F,B,R2 } \\
& \text { 3. المبحث الثاني: التخطيط الاستراتيجي للتسويق } \\
& 1.3 \text { مفهوم التخطيط الاستراتيجي للتسويق }
\end{aligned}
$$




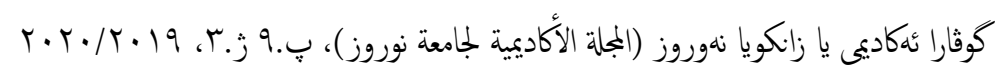

تعني رسالة التسويق كيف تتواصل المنظمة مع جمهورها المستهدف للتحدث عن نسها وعن ما تفعلة، إذ تشتمل الرسالة التسويقية على بيان تحديد المواقع وبعض النقاط التي تدعها، وتعمل الرسالة على تحويل بيان تحديد المواقع إلى سلسلة من الرسائل الرئيسية التي يُّكن أن يستخدها المسوقون فُيْ إعداد مواد للتواصل التسويتي كالنشرات الصحفية وشعارات الإعلانات ومشاركات وسائل التواصل Kotler\& Keller, 2006: ) الاجتاعي والبرامج النصية ونسخ الإعلانات والح

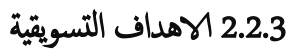

تسعى أي منظمة المى تحقيق أهدافها التسويقية كالربح ، أو تقّديم الخدمات إلى الزبائن و وتستمد الوحدات التنظيمة من الهدف العام الأهْداف التي ترغب في تحتيقها، وتسعى العملية التسويقية إلى تحقيق عدة أهداف تتمثل في الاتي: :(Donnelly\& Peter, 2007: 55)

$$
\text { - - - م إثباع حاجات ورغبات الأفراد في المجتع وكسب رضاهم. }
$$

هناك نوعان من الأهداف يتم تحديدها على مستوى إدارة التسويق: (الصيرفي،

(222:2005

أ- الأهداف المالية: وتتعلق كثيرا بمعدل المردودية في الآجال الطوية، القصيرة،

$$
\text { المتوســطة، الندفق، النقدي و الأرباح التسويقية. }
$$

ب- الأهداف التسويقية: و ترتكز على الأهداف المالية السابقة و تتزبم في رق أعال مبيعات، حصة السوق، و منها كذلك التغطية، التوزيع، صورة المنظمة،

$$
\text { الشهرة.... الخ. }
$$

وعموما هناك ثلاثة أنواع رئيسية لأهداف الاستراتيجية التسويقية وهي: (الصحن

$$
\text { والسيد، 2000: 371): }
$$

أ- أهداف المردودية و القائد على الاستثُار : و هي أهداف مالية. فأهداف المردودية تتحدد بأهداف ربحية ، الإيراد على رأس المال المستثمر أو كذلك بمدى مساهمة المنتجات في النكليف الثابتة و أرباح المنظمة ، فأهداف المساهمة قد تتشكل بقيم مطلقة أو بنسبة من رثٌ الإعال مثال ذلك الحفاظ
والتخطيط الاستراتيجي اللتسويق بإنه عبارة عن عملية إدارة تؤخح مجموع الفعاليات والانشطة التسويقية لادامة العلاقات بين أهداف المنظمة والفرص التسويقية المتغيرة وذلك لضمان الاستقرار وعدم التعارض ومن ثم سلامة تنفيذ وتحقيق الاهداف

(مالك وعبيد، 2017: (10) (10).

وعرف (احم، 2017: 183) التخطيط الاستراتيجي للتسويق بكونه عبارة عن تصميم الاهداف التسويقية وأهداف التكنولوجيا الحيوية وتصميم البدائل الاستراتيجي التسويقية التي تأخذ شكل خطط قصيرة ومتوسطة وطويلة الاجل وكذلك تخطيط البرامج التي توائم معها، ثخ المفاضلة بينها لحسن اختيار انسبها ومراجعتها وذلك للتحقق من تنفيذ أهدافها الخطططة. ثانياً: أهمية النخطيط الاستراتيجي للتسويق بين كل من (العوامرة والزيادات، 2012: 113) ان اهمية التخطيط الاستراتيجي للتسويق تكمن في الاتي: - - يقوم بتحديد الانشطة اللازمَة لتحقيق أهدافْ المنظمَة الانتاجية كونة يربط

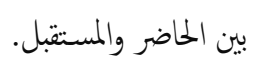

- - يعتبر المحور الاساسي لنجاح جميع الوظائف الاخرى كونه الركيزة الاساسية لأنجاز الوظائف المراد تحقيقها عبر بمحوعة متكاملة من الانشطة المرتبطة

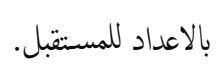

- - المساهمة في تقديم قاعدة بيانات متكمالة للخطط الخخى. - - تمكين منظمات الاعمال من القدرة على التكيف مع متغيرات البيئة وخصوصاً الخارجية.

- - تلبية رغبات وإذواق ومتطلبات الاسواق المستهدفة. - - ميتبر اداة فاعلة للنغلب على الاوضاع المعقدة. - - تهيئة واستعداد المنظمة للاستجابة للتغيير. - - تحتيق المزايا التنافسية مثل جعل المُظمة في وضع إستباقي من خلال حصولها على الكفاءات التي تحتاجحا في كافة مواردها. 2.3 ابعاد التخطيط الاستراتيجي للتسويق 


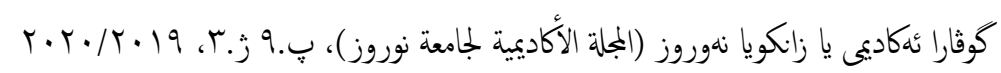

هي عملية التخطيط كإعلان مكتوب يحدد الاسواق المستهدفة خاصة اسواق المنتجات الفردية ، وتجميع الارباح وفقاً لوحدات العمل الاستراتيجية التي تحتوي على عناصر الجدولة للمزيج التسويقي من خُلال العمل معاً على إنشاء برنامج

تسويقي (Veresová, 2002: 14 (16). الخطط الاستراتيجية التسويقية تَتضمن بمحوعة من الخصاص تساعدها على تحقيق

$$
\text { النجاح وهي الاتي (احم، 2017: 209): }
$$

المرونة: ويعني أن تكون الخطة التسويقية مرنة قابلة للنعديل وفقا لتغير

الظروف المستقبلية والمنتظمة مسارات عدة لتحقيق اهدافها المطلوبة.

البساطة: حيث ينبني ان تتمتع الخطة التسويقية بالسهولة واليسر بحيث تُكن جميع العَاملين في المنظمة من فهمها واستيعابها لامكانية تَطبيقها على

$$
\text { ارضُ الوَاقع فهي بديل تسترشد بة جميع القوى العاملة. }
$$

وضوح الاهداف: يتضمن أن تكون الخطة التسويقية الاستراتيجية واضحة الاهداف بعيدة عن العشوائية إذ كلما اعتمدت هذه الخطة على التنبؤ

$$
\text { المعلوماتي والمعرفي كلماكانت أكثر نجاحاً. }
$$

الواقعية: تعتمد على التنبؤات المنطقية دون المبالغة أي الانجاز، بالاضافة الى

$$
\text { الدقة والشمولية ومستقبلية الخطة التسويقية واستدامتها. }
$$

5.2.3 الرقابة

تعد الرقابة بمثابة الحلقة الأخيرة التي تكمل بها الاستراتيجية التسويقية، و هي التأكد من أن الأهدَاف المُسيطرة في الاستراتيجية التسويقية مطابقة لما حدث في الواقع العملي لها، وهي بذلك توفر العديد من المعلومات التي تظهر نْقاط القوَة والضُعف في التنفيذ قصد معالجها و منع تكرار حدوثها. إذ تعرف الرقابة التسويقية عَلى أنها:" عملية قياس وتقييم نتائج الاستراتيجيات والخطط التسويقية واتخإذ الإجراءات التصحيحية للنأكد من أنَ الأهداف التسويقية قد تحَ تحقيقها (الصحن

$$
\begin{aligned}
& \text { والسيد، 2000: 371). } \\
& \text { 4. المبحث الثالث: الاداء التسويتي } \\
& 1.4 \text { مفهوم الاداء التسويتي }
\end{aligned}
$$

الأداء هو مفهوم واسع لارتباطه الواسع والشامل بالكثير من المفاهيم ، فهو يعكس مهرك قدرة وقابلية المتظمة على آستغلال مواردها الماليةَ والمادية والبشرية والمعلوماتية
على مساهمة المنتج (س) عَلن الأقل ب 30\% من رق الأعمال خلال الثلاث

$$
\text { سنوات القادمة . }
$$

ب- أهداف الحجم و حصة السوق: و هي مرتبطة بالحجم المرغوب في السوق المعني، أهداف هذا الصنف قد تتشكل بالتناوب او سوياً على حسب :

$$
\text { رجم المبيعات ( بالطن، الوحدات المباعة...احخ ). }
$$

3.2.3 الحيار الاستراتيجي للتسويق

هي حالةًَ ناتجةً عن المقابلة بين نقاطْ القوة والضعف الداخليةً للمُنظمة من نجة والفرص والتهديدات الخارجية لها من بجة اخرى اي التحليل البيئي للمنظمة (يوسف والصميدعي، 2014: 141-143) وعليه مفهوم الخيار الاستراتيجي للتسويق لابد من مراعاة الإتي:

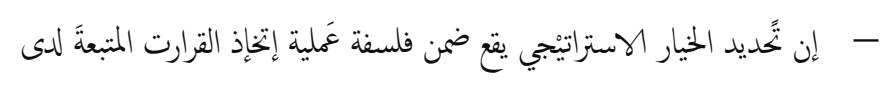
المنظمة.

- - يخضع للفلسفة الايدولوجية الطموحات والقيم والإدراك لدى الجماعات المسيطرة أو مراكز القوَى داخل المنظمةَ.

- - يعتمد نوع الخيار الاستراتيجي على العلاقةَ بين أعضاء وجمهور المنظمة والبيئًَ المّحيطة.

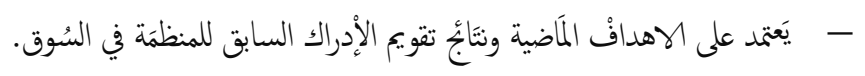
- - نَع الاهداف الاستراتيجية والتكتيكةً المراد الوصول اليها وتُختقها من قتّل المنظمة.

- - مُستوى طمّوح الذي تستى اليه المنظمة وخاصة الجهاعات المُّيطرة أو مرَاكز

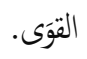
- - درجة التكيف المُظمة مع بينتها الخنارجيةَ مَن خلال نوع القُّرات والامكنينات والسلوك الذي يَقود الى التكيئف أولاً وكْيفية القرار ثانياً. - مُستوى التأثنير على الفئات الاجتَّاعية والثقافيةَ المختلفة.

4.2.3 الخطة التسويقية 


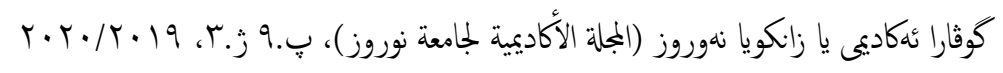

ويعد الاداء التسويتي بكونة درجة نجاح المنظمة في السُوق والتي تتحقق بواسطة

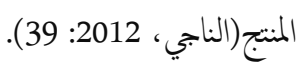
ويشير (يميى، 2012: 41) بان الاداء التسويقي يمثل مستوى تحقيق الشركه لأهدافها الموضوعة في الخطة التسويقية.

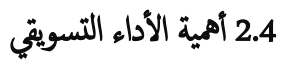

تعد إدارة التسويق من أهْمُ الإدارات التي تتواجد في المنظمة نظرآلاعتاد تواجدها عُلى تحقيق أهدافها وبقاءها وإستمرارها وكسب الميزة التنافسية في الأسواق ، لذا فان حسن تنظيمها وتنمية أداءها التسويتي بشكل مستمر أصبح في الوقت الحاضر منَ الحاجات الملحة والضرورية لموابهة تحديات التنافس وايجاد الفرص. وفي ظل التطورات الكبيرة التي شَهدا العالم اقتصادياً وإجتماعياً وثقافياً وتكنولوجياً ، باتت منظطات الاعمَال تسعى الى تحسين ادائها وبناء مكانة ذهنية متميزة، ويفهم من المكانة الذهنية بكونها بجموعة من الأحاسيس والإدراكات والإطباعات التي يكونها المستهالكون عن منتج ما، من خلال مُقارنته معَ المنتجات الأخرى المنافسة ، حيث تتركز مكانته في إذهان الزبائن بمساعدة او دون مساعدة التسويقيين الذين يخططون من أجلْ أن يُعطوا لمنتجاتهم المكانة التي توفر لهم الميزة الأكبر في الههداف السوقية

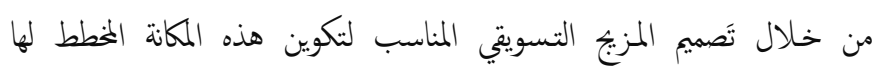
(الزيواني، 2004: 109). (ال)

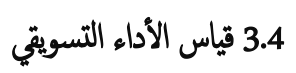
تكمن مشكة قياس الأداء التسويقي في تحديد المقايس والإجراءات الافضل، وكذلك في وضع مقاييس داخلية وخارجية للسوق ومراجعتها دورياً للمتأكد من كونها تسير على نَو افضل، إذ إن عمة القياس ليست بالأمر السهل وفق متغيرات عديدة ومتنوعة قابلة للنغيير والتبديل ، وفي ظروف متباينة في طبيعها ، واشكالها. وإن ما كا تمتاز به منظات الأعمال التي تنتج بمستوى عالمي هو قدرتها على تكرار وأستمرارية نجاحما، وتحسين ادائها بشكل ثابت ، لذلك فان إمتلاكها لنظام شامل من المقاييس لقياس الأداء يعدّ امراً ضرورياً، خصوصاً إذ ما اريد تحقيق مضاعفة الأداء بمقدار خمسة او عشرة اضعاف الأداء الحالي (الزيواني، 2004: 111).

إن قياس الأداء التسويقي هي عملية تتم خلاله تزويد التغذية العكسية عن أداء

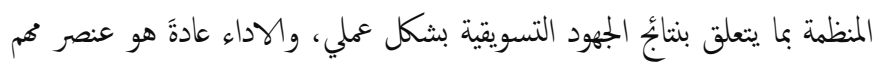
لميزانية المنظمة وحوافز للافراد التنفيذين (الناجي، 2012: 40).
بالشكل الأمثل أملاً في الؤصول إلى غاياتها المنشودة ،والتي تمكنها من النمو والبتقاء، ومنافسة المنظات، وتوجد في عالم الإعال اليوم أنظمة قياس تتصف بالخصوصية وتنفرد فيها منظات دون غيرها، وربما تمثل نقطة قوة اساسية لمثل هذه المنظلات، ويكن وضع هذه الأظمة في إطار توبهين أساسيين فهناك أنظمة القياس ذات التوجه التقليدي واخرى ذات توجحات حديثة إنبثقت من التطور الحاصل في انظمة القياس التقليدية (النقشبندي، 2010: 54). وَيعد الاداء التسويقي على وفق اتفاق الكناب والباحثون مفهوماً جوهرياً في إطار أدبيات الادارة، لما له من إرتباط وثيق بوجود المتظمة وفاعليتها ،وفي تَقيق أهدافها المتثثلة بالبقاء والتكيف والمنو، وهذا ما يَجعل المنظمة تسعى وبشكل متواصل لتحسين أدائها التسويقي، وذلك من خلال خفض الكّلف والابتكار والابَّاع في المنتجات والعمليات مع تَّسين الجودةً الانتاجية من أجل زيادة قدراتها التنافسية (الفهادي، 41:2005). أن الاداء التسويقي يعكس درجة نَاح المنظمة أو فشلها، وذلك من خلال سعها وقُدرتها على تحتيق الأهداف المتمثلة بالبقاء والتُكيف مع متَغيرات البيئة لا سيا وإن المنظلات المعاصرة تواجه بيئة سريعة التغير في متطلبانها ومواردها وفي ججم الطلب والثنوع في مواصفاته ، فضلاً عن مَا يواجه المنظمة من منافسة حادة في الاسواق ، الامر الذي فرض عليها توجحاً لتطوير تقنياتها وإمكانها لضان القُدرة على الاستجابة لمتغيرات البيئة والأسواق وتحتيق الأهداف ، ويككن التأكد من ذلك واهكانية تحقيقّه من خلال قياس الاداء التسويتي للمنظمة (الزيواني، 2004: 110). ويعرف الأداء التسويقي بإنه عملية دراسة وتحليل جميع عناصر العمليـــة التسويقية للوقوف على إيهابيات وسـلبيات الأداء التسويقي (مراكز القوةَ والضُعف في النشاط) بهدف إتخإذ القرار المناسب في الوقت المناسب وبالنكلةة المناسبة (هامان،

.) $153: 2003$ ويرى (الزيواني، 2004: 111) إن الاداء التسويقي يمثل الوسيط بين التغير والتكيف البيئي، أو تَطوير للألية التي يُمكن للمنظمة من خلالها التكيف مع متغيرات البيئة الحارجية من أجل تحقيق الأهداف.

وييين (الفهادي، 2005: 41) بإن الاداء التسويقي يمثل محصلة لكثافة العمليات التي تقوم بها المنظمة وأي خلل في اي منها لابد ان يؤشره الاداء باعتباره مرآة. 


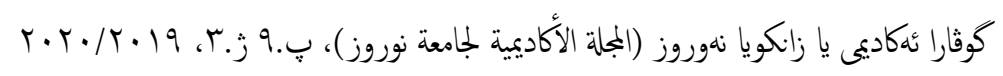

- - - - - -

$$
\text { منظطات أخرى منافسة. }
$$

- - - -يولد الاهتمام برضا الزبون القدرة على حهاية نفسه من المنافسين خصوصاً

$$
\text { المنافسة السعرية. }
$$

- - - المنظمة التي تسعى إلى قياس رضا الزبون ستتمن من تحديد حصتها السوقية. - - - -مثل رضا الزبون تغذية عكسية للمنظمة خُاصة فيما يتعلق بتطوير المنتجات

$$
\text { المقدمة الى الزبون. }
$$

\subsection{4 ولاء الزبون}

أظهرت مقايس ولاء الزبون المزيد من الاهتمام بوصفها مقياساً جيداً للأداء التسويقي ، وقد لاحظ المدافعون عن الولاء بإن الأداء المالي يعكس عموما مدى تكرار شراء الزبائن من المنظمة المعنية مَعْرُور الزمن بغض النظر عن حالة الرضا ، واقتزح احد اكثر المدافعين عن هذه الفكرة بإن التسويق الجيد يجذب الزبائن المناسبين، وهم الذين يظهرون ولاءهم المنظمة ، وبذلك يكونون مربحين لها ويكن الاحتفاظ بهم

$$
\text { (خنشور، 2006: 382) - (خن). }
$$

ويرى (الزيواني، 2004: 134) إن ولاء الزبون متغبر سلوكي يمثل حالة غير ملمؤسة ، لا يّمكن تحديد أبعادها بُشكل مادي ، بل يستدل عليها من خلال مُمارسات معينة وظواهر معينة ، تتمثل بتَوجه الزبون الإيجابي والفعال نخو منظمة او علامَة ما

$$
\text { والاخلاص لها والإنشداد نخوها. }
$$

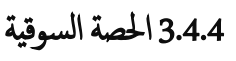

تمثل الحصة السوقية احد المؤشرات المهمة التي تعزز المركز التنافسي للمُتَظمة، فالمنظات بصورة عامة تسعى للمحافظة على حصتها في السوّق او زيادتها من خلال تقديم السلع والخدمات المناسبة جودةَ وسعراً، وتطوير إنشطتها وفعالياتها بما يتناسب مع حاجات السوق وتوقعات الزبائن، فالحصة السوقية تمثل مؤشراً فاعلاً لقياس مدى لحى نجاح المنظمة وقدرتها على تحقيق النفرد والريح في السوق. إن الحصة السوقية تمثل المقياس الأفضل لقيّاس الأداء التسوُّيقي لُمنظمَات الأعمال والتي نرى عن طريقها ربحية المنظمة وقدرتها على تحقيق أهدافها والحصة السوقية هي مقياس هم للإداء وأنها من مقايس الإداء الجيد، والتي يتم من خلالها التميزيز بين المنظمات النابحة وغير الناجحة في نشاطها (الناجي، 2012: 45).
إن قياس الاداء يكن الجهاز الاداري من إتخإذ القرارات الرشيدة، وذلك عن طَريق تزويدهم بمعلومات حول الاداء والعمل والتشغيل وكفاءة نشاطات المنظمة وفاعليتها، وكذلك يتم وضع الميزانيات السنوية على المَدى البعيد ،وتخصيص الموارد والنفقات التي تُعد أساساً للمتابعة وإتخإذ الإجراءات التصحيحية والمسائلة ومحاسبة المنظات في إنفاقها للأموال التي تخصص لها (الفهادي،2005: 44).

\section{4 ابعاد الاداء التسويتي

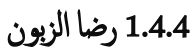
رضا الزبون من الموضوعات التي تبنته المنظمات بوصفه مقياساً لاداء الأعمال ، واحد مقايس المخرجات غير المالية ، ويعكس رضا الزبون تصورات الزبائن عن العروض التي تُقدها المنظمة ، لا سيا وإن المنظات اليوم تعمل في بيئة حادة المنافسة ، وسريعة التغيير ، مما تضطر للتزكيز على رضا الزبائن على نحو افضل من منافسين أخرين ، وإن الرضا لا يعني قناعة الزبون بجانب واحد ، وإنما يكون الرضا حالة معبرة عن جميع الووجه والجوانب التي يمكن قياسها وتحليلها لإقرار مستوى الرضا المطلوب ، وإن انخفاض رضا الزبون او عدم تناميه بمعدل ما يقدمه المنافسون إذ ينعكس على الأداء التَّويقي للمنظمة. وفي مجال التأكيد على موضوع رضا الزبون ، أشار البعض الى إنه ينظر للزبون بوصفه آحد الأصُول المهمة للمنظمة وإنه مقارن مرجعي في العديد من النشاطات ، وإن للزبائن توقعات معينة يضعونها في إذهانهم قبل اتخإذهم لقرار الشراء ، ويكونون أكثر رضا إذ ما زادت الفوائد التي يحصلون عليها عند شرائهم لسلعة أو خدمة ما على مستوى توقعاتهه، إذ أن امتلاك قاعدة من الزبائن الراضين تعد اصولاً تسويقية عمة فيما يضيفه من عوائد ومن خفض للنكليف التسويقية(الزيواني، 2004: 124). وتكمن أهمية رضا الزبون للمنظمة بالآتي (النقشبندي ,2010: 64) - - - - - - - إكان الزبون راضياًعن المنظمة فأنه سيتحدث إلى زبائن اخرين مما يولد زبائن جدد. - - - - يؤدي رضا الزَبون عن المُنتج المقدم إليه من قبَل المنظمة إلى ان قراره بالعودة إليها سيكون راضياً. 


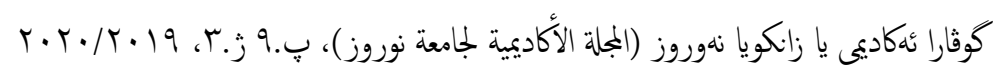

في الحالة الثانية مبادأة وقد تجمع المنظمة بين النوعين اذا كانت تتعامل مع أكثر

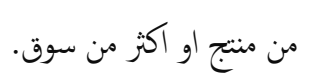

التصنيف حسب نوع المنتج: اذ يككن ان يكون التسويق الابنكاري في مجال السلع او في مجال الخدمات او في مجال المنظمات او في مجال الاشخاص او

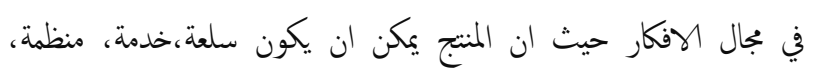
شخصاً، فكرة ، وذلك طبقا للمفهوم الموسع للتسويق.

التصنيف حسب نوع العميل: يكن ان يتم تقسيم التسويق الابتكاري حسب نوع العميل المستهدف ، أي تسويق موجه للمستهاكين النهائين (الافراد) وتسويق ابتكاري موجه للمستتمرين الصناعيين (المنظلات) ـ وعادة نجد ان التسويق الابتكاري الموجه للمستهلك النهائي يعتمد على اثارة الدوافع العاطفية غير الرشيدة اكثر من اعتمده على اثارة الدوافع العقلانية الرشيدة والعكس

$$
\text { صحيح بالنسبة للمستثمين الصناعين. }
$$

\section{5. المبحث الرابع: وصف وتحليل نتابج البحث واختبار الفرضيات}

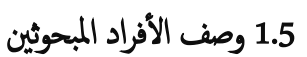

إنسجاماً مع توجحات البحث تح توزيع إستارة الاستبانة على الأفراد المبحوثين، وقد بلغ عدد الاستمارات الموزعة (60) إستارة على الافراد ذوي العلاقة بالموضوع إعيد منها (50) استمارة صالحة للنحليل من مجموع الاستارات الموزعة، تمثلت عينة البحث بالموظفين في مصارف محافظة دهولك، والجدول (1) يقدم وَصف تفصيلي

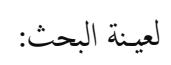

الجدول 1

\begin{tabular}{|c|c|c|}
\hline النسبة & 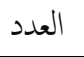 & توزيع الأفراد المبحوثين حسب \\
\hline 66.0 & 33 & الجنس \\
\hline 34.0 & 17 & انثى \\
\hline 8.0 & 4 & أقل من 25 سنة \\
\hline 48.0 & 24 & 25-35 سنة \\
\hline 30.0 & 15 & 36-46 سنة \\
\hline 13.2 & 7 & آكثر من 47 سنة \\
\hline 6.0 & 3 & المستوى العلمي \\
\hline 82.0 & 41 & بكاوريوس \\
\hline 12.0 & 6 & دبلوم \\
\hline 40.0 & 20 & مدة الخدمة \\
\hline
\end{tabular}

وصف أفراد عينة الدراسة

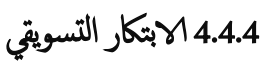

إن الابنكار التسويقي مفهوم واسع ،ويدخل في جميع أوجه النشاط التسويقي، ومن ثم فهو غير مقتصر على مجال معين في التسويق، كلابتكار في مجال المنتج أو في مجال الإعلان فقط، وإنما يشمل جميع المجالات التسويقية الأخرى، وهو يمس كل الأنشطة المرتبطة بتوجيه المنتج من المنتج إلى الزبون، أي وضع أفكار جديدة أو غير تقليدية في المارسات التسويقية، وهذا يعني أن أي ابنكار تسويقي ينطلق من فكرة جديدة ولا يتوقف عند حد توليد أو إيجاد فكرة جديدة، وإنما يتعدى ذلك إلى وضع هذه الفكرة موضع التطبيق العملي، ويعرف على أنه الاستغلال الناجح للأفكار الجديدة، وبالطبع في مجال التسويق وبهدف الابتكار التسويقي إلى إرضاء المستهاكين بشكل أفضل من المنافسين من خلال البراعة في تحديد وتلبية حاجاتهم ورغباتهم بشكل دقيق، والمواءمة بينها وبين قدرات وإمكانيات المنظمة. كما أنه يسعى إلى أن يخلق العرض الطلب (العرض الإبداعي)، وإذا كان الهدف الأساسي للتسويق هو تلبية الحاجات الحالية للمستهلكين بما يتلاءم مع قدرات وأهداف المنظمة (سليليني، 2007:

ويرى (الفهادي، 2005: 11) أن لتصنيف التسويق الابتكري اربعة انواع وهي: التصنيف حسب نوع المنظمة: يمكن ان يتم تقسيها حسب نوع المنظمة التي

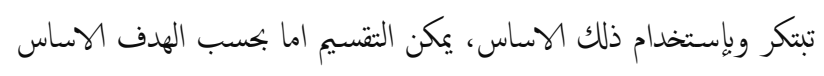
للمنظمة ، فقد يكون التسويق الابنكاري في منظمة تهدف الى الريح او منظمة لا تهدف الى الريخ ويكن التقسيم حسب النشاط الاساس للمنظمة

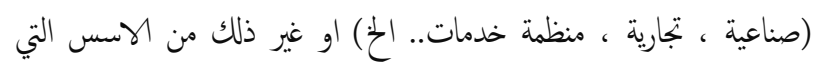
يككن استخداهما في تقسيم المنظات مثل (نوع الملكية) وقد يكون التسويق الابنكاري الذي يصلح لمنظمة معينة لا يصلح لمنظمة من نوع آخر . التسويق الابنكاري حسب نوع الهدف: طبقا للهدف من وراء التسويق الابتكاري يككن تصنيفه الى تسويق ابنكاري بهدف الى حل مشكلة معينة تواجهها المنظمة او مواجهة ظاهرة غير مرغوب فيها تعاني منها المنظمة مثل

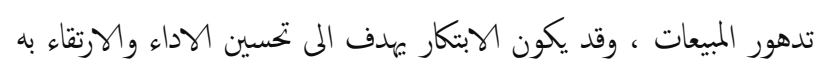
وبالتالي فإن التسويق الابتكري في الحالة الوولى يكون رد فعل بينا يكون 


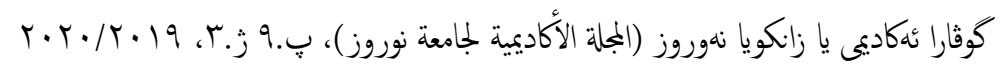

إتفاق أفُراد العينة مع هذا المتغير ، إذ زادَ الوسط الحسابي العام عن الوسط الفرضي ( 3 ) على مقياس ليكرت المُاسي المعتمد في البحث، وقد أسهم في ايجَابية هذا المتغير كل من (X19) بوسَط حسابي قدره (4.64) وبإنراف معياري (0.563)، والذي يشير إلى قيام المنظات المصرفية بالاعتاد على الرقابة في إعادة تكيفها الاستراتيجي ، أما أقل قيمة للمتوسط الحسابي خفقتها الفقرة (X5) اي تنصب الرقابة على تشخيص مكانة الخللل بوَََط حسابي قَدره (3.64) وبإنحراف معياري (1.258). ومن تفحص قيم الانحرافات المعيارية لإجآبات المبحوثين يتيبن إنها هناك

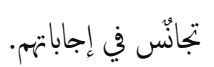

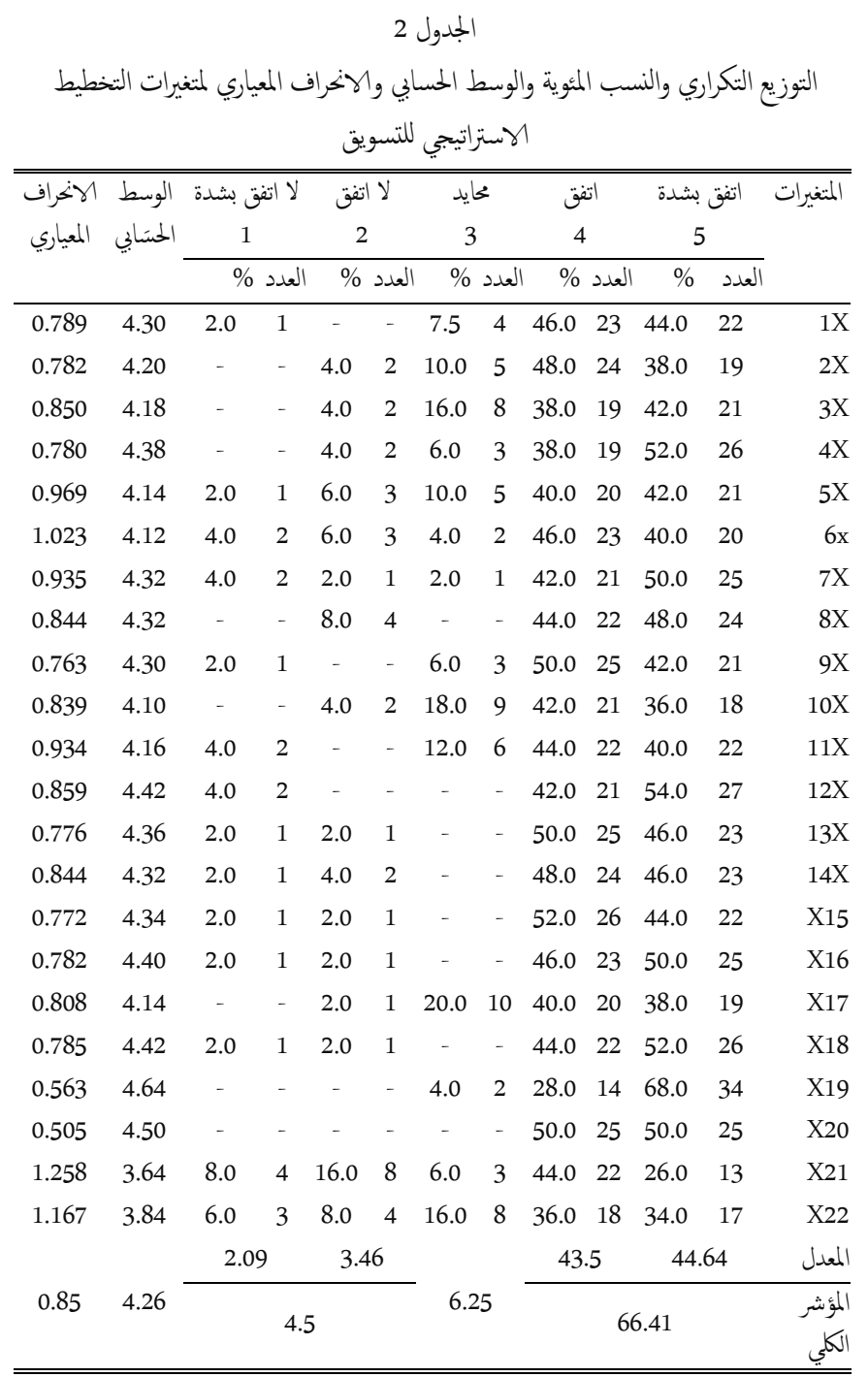

المصدر: بالاعتاد على نتانج

3.5 وصف متغير الاداء التسويقي
$48.0 \quad 24 \quad 11-15$

أكثر من 16 سنة 12.0

تشير نتانُج الجدول ( 1) الى الاتي:

الجنس: يتيبن بأن الأفراد المبحوثين من فئة الذُور بلغت نسبتهم (66.0\%)، أما فئة الإناث فبلغت نسبته (34.0\%) من المجمّوع الكلي للافراد عينة البَحث، مما يعني إعتاد المصارف المبحوثة على فئة الذكور مقارنة بفئة الاناث. العمر: يتبين بإن أكثر فئة عمرية ظهوراً هي الفئة (35- 25 سنة) حيثُ بلغُت نسبة هذه الفئة (48.0\%) من الأفراد المبحوثين، يليها الفئة (36- 46) والتي بلغت (30.0\%)، يليها الفئة (أكثر من 47 سنة) والتي بَلغت (14.0\%)، والفئة الأقل ظهوراً هي الفئة الاولى والاخيرة (أقل من 25 سنة) التي بلغت نسبتها (8.0\%). المستوى العلمي: يتيين يان معظم أفراد عينة الدراسة يحملون شهادة البكالوريوس حيث بلغت نسبة هؤلاء (82.0\%) من الأفراد المبحوثين، وبلغت نسبة حاملي شهادة الدبلوم (12.0\%)، أما فُئة شهادة الماجستير فبلغت نسبتها (6.0\%) وما سبق يعطي مؤشراً جيداً بإن المصارف المَحوثةً

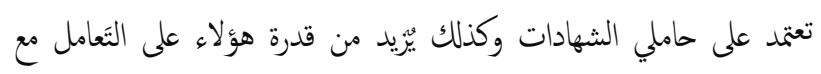
أسئلة الاستبانة ومتغيراتها. سنوات الخدمة الإجالية: يتين بأن الأفراد الذين تبلغ مدة خدمتهم الإجالية في المنظمة (15-11سنة) هم الذين شكلوا النسبة الاعلى من الأفراد المبّحوثين، وبلغت هذه النسبة (48.0\%)، وبلغت نسبة الافراد التي تتزاوح مدة خدمته(5- 10 سنة) (40.0)، أما سبة الأفراد التي تبلغ مدة خدنته الاججالية (16 سنة فاكثز ) (12.0\%). 2.5 وصف متغير التخطيط الاستراتيجي للتسويق تُشير ننائُ الجدول (2) الذي يمثل التوزيع التكراري والنسبة المئَية والوسط الحسابي والانحراف المعياري للمتغيرات (X1-X22) التي تُمثل العبارات الخاصة بالتخطيط الاستراتيجي للتسويق ، إلى إن (66.41\%) من أفراد عيئة البحث متفقون مع هذا المتغير ، وبلغ معدل المحايدين (6.25\%) ، فيا بلغ معدل غير المتنقين (4.5\%) ، وبوَسط حسابي (4.25) ، وانحراف معياري قدره (0.85) ، مما يعني 


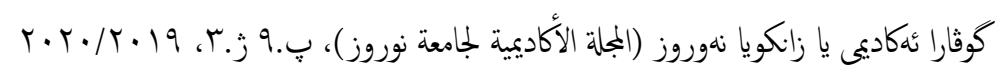

\begin{tabular}{|c|c|c|}
\hline 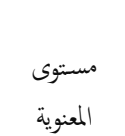 & سبرامل ارتباط & الفرضياتspss \\
\hline 0,000 & $0.523^{* *}$ & تُوجدم علاقة ارتباط معنوية بين ابعاد التخطيط الاستراتيجي اللتسويق \\
\hline 0,000 & $0.612^{* *}$ & توجد علاقة ارتباط مَعنوية بين الرسالة التسويقية والأداء التسويقي مجمعة \\
\hline 0,000 & $0.618^{* *}$ & توجد علاقة ارتباط معنوية بين الأهداف التسويقية والأداء التسويقي مجتمعة \\
\hline 0,000 & $0.630^{* *}$ & التسويد علاقة ارتباط معنوية بين الخيار الاستراتيجي للتسويق والأداء \\
\hline 0,000 & $0.546^{* *}$ & توجد علاقة ارتباط معنوية بين الخطة التسويقية والأداء التسويقي مُجتمعة \\
\hline 0,000 & $0.561^{* *}$ & توجد علاقة ارتباط معنوية بين الرقابة التسويقية والأداء التسويقي مجتَعة \\
\hline & $\mathrm{N}=50$ & 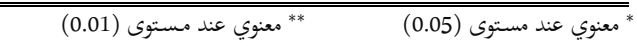 \\
\hline
\end{tabular}

المصدر: بالاعتاد على نتائج

تشير ننائُ الجدول (4) إلى وجود علاقة إرتباط معنوية بين التخطيط الاستَاتيجي للتسويت مجتمعة والاداء التسويقي مجتمعة ، وبلغت قيمة معامل إرتباط المؤشر الكلي (0.523**) عند مستوى معنوية (0.000)، مما يعني بإنه كُلما زاد إهتمام المنظمَات المبحوثة بالتخطيط الاستراتيجي للتسويق أدى ذلك الى تحسين أدائها التسويقي. اما بالنسبة لعلاقات الإرتباط بِن أبعاد التخطيط الاستراتيجي للتسويق منفردة (الرسالة التسويقية، الاهداف التسويقية، الخيار الاستراتيجي، الخطة التسويقية، الرقابة التسويقية) والاداء التسويقي مجمعة فتشير المعطيات على وجود علاقة إرتباط

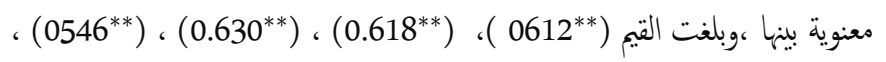
(0.561**) وعنَّ مُستوى معنوية (0.01،وتعكس القيم أعلاه قوة العلاقة والانسجام بين التخطيط الاستراتيجي للتسويق التي تعتمها المنظات المبحوثة والقدرة على تحقيق الاداء التَسويتي .وعليه تقبل فرضية الإرتباط الرئيسة الاولى والفرضيات الفرعية المنبثقة منها.

وتعزو الباحثة ننائُ علاقات الإرتباط السابقة المى إن اهتمام المنظات المبحوثة بأبعاد التخطيط الاستراتيجي للتسويق تؤدي الى تعزيز الاداء التسويقي ، وبذلك فالتخطيط الاستراتيجي اللتسويق تشكل أساس العمل في المُنْظمَات المبحوثة وبما يتلاءم مع متطلبات الزبائن، ويساهم أيضاً على تحقيق أهداف المنظمة التي تسعى إلى تحقيقها، ومواكبكة التغرات المتسارعة في بيتهنها ، وقد ادى دور التخطيط الاستراتيُجي للتسويق في منظات اليوم تغيير وجه الممارسة الإدارية، وإعتمد فلسفة مفادها إطلاق الطاقات الكامنة لدى العاملين على الاصعدة كافَة من أجل اخراج أفضل ما لديهم من محارات وخبرات وإمكانيات ووضعها في تطوير المنظمة. تُشير نَنائج الجدوّل (3) الذي يمثل التوزيع النكراري والنستب المئوية والوسطْ الحسَابي والانخراف المعياري للمتغيرات (X37 - X23) التي تمثل العبارات الخاصة بالاداء التسويقي، إلى إن ( 60\%) من أفراد عينة البحث متفقون مع هذا المتغير، وبلغ معدل المحايدين (6.7\%) ، فيا بلغ معدل غير المتفقين (7.87\%) ، وبوسط حسابي (4.043) ، وإنحراف معياري قدره (0.86) محا يعني اتفاق أفراد العينة مع هذا المتغير ، إذ زاد الوسط الحسابي العام عن الوسط الفرضي ( 3 ) على مَقِئس ليكرت الحُّاسي المعتمد في البحث، وقد أسهَم في إيجابية هذا المتغير الفقرة (X29)، والتي تُشير الى قيام المنظات المصرفية بالتركيز على بناء الثقة مع الزبائن، وبوسط حسابي قدره (4.68) وإنحراف معياري قدره (0.471)، أما أقل قيمة للمتوسط الحسابي فقد حقتها الفقرة (X37) والتي تُشير الى قيام المنظات المصرفية بالاعتماد على تَكنولوجيا المَعلوُّات في توزيع خدماتها على الزبائن بوسط حسَابي قَدره (2.66) وبانخراف معياري (1.349). ومن تفحص قيم الانخرافات المعيارية لإجابات المبحوثين يتيين بأن هناك هناك تجانس في إجاباتهم

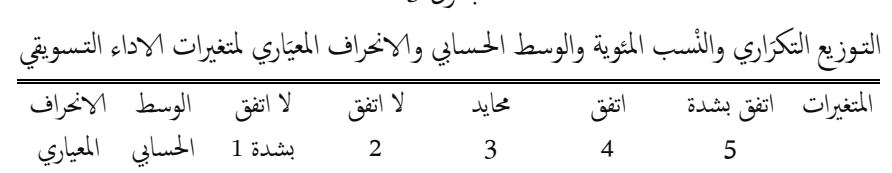

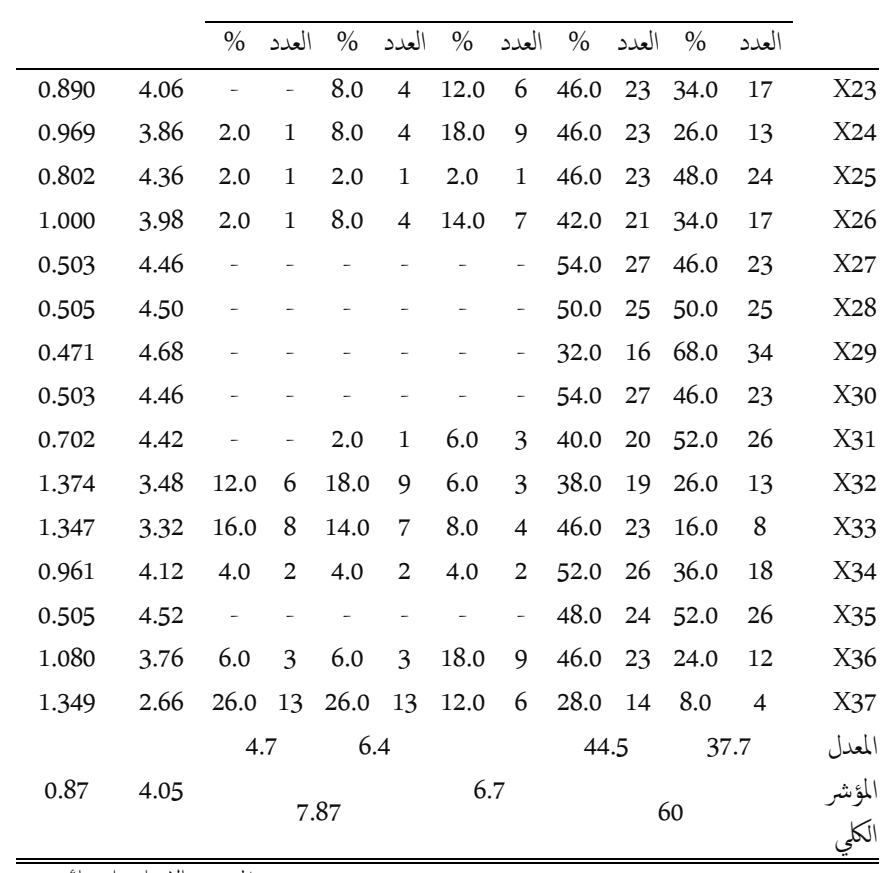
spss المصدر: بالاعتاد على نتانُ

4.5 اختبار فرضيات الإرتباط الجدول 4 علاقات الإرتباط بين التخطيط الاستراتيجي للتسويق والأداء التسويقي 


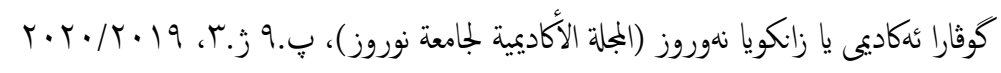

(2.0105)، كما إن مستوى المعنوية المحسوبة والبالغة (0.000)، كانت أقل

5.5

من مُستوى المعنوية المُستخدمة في البحث والبالغة (0.05)، وعزز ذلك رلك قيمة (B) والبالغة (0.671)،ما يعني إن إهتمام المصارف بالرسالة التسويقية بمقدار وحدة واحدة ستؤدي الى زيادة إجالي الاداء التسويقي بمقدار (0.671)، وبتلغت قيمة معامل التحديد (0.505) محا يعني إن (50.5\%) من التباين الذي يحدث في الاداء التسويتي تفسره الرسالة التسويقية ،أما الباتي والبالخ (49.5\%) تفسره متغيرات اخرى لم يتناوله البحث. وجود تأثير معنوي موجب للأهداف التسويقية في الاداء التسويقي مجتمعة، إذْ بلغت قيمة (T) المحسوبة (6.620) وهي أكبر من قيمها الجدولية والبالغة (2.0105)، كما إن مستوى المعنوية المحسوبة والبالغة (0.000). كانت أقل من مستوى المعنوية المستختخدة في البحث والبالغة (0.05)، وعزز ذلك قيمة (B) والبالغة (0.526)، مما يعني إن إهتخام المصارف بالأهداف التسويقية بمقدار وحدة واحدة ستؤدي إلى زيادة إجلاي الاداء التسويقي بعقدار (0.526)، وبلغت قيمة معامل التحديد (R2) (0.493) مما يعني إن (49.3\%) من التباين الذي يحدث في الاداء التسويقي يفسره الاهداف التسويقية، أما الباتي والبالخ (50.7\%) تفسره متفيرات أخرى لم يتناوله البحث. وجود تأثير معنوي موجب للخيار الاستراتيجي للتسويق في الاداء التسويتي مجتمعة، إذ بلغت قيمة (T) المسوبة (5.211) وهي أكبر من قيمها الجدولية والبالغة (2.0105)، كما إن مستوى المعنوية المحسوبة والبالغة (0.000)، كانت أقل من مستوكَ المعنوية المستخدمة للبحث والبالغة (0.05)، وعزز ذلك قيمة (B) والبالغة (0.454)، مما يعني إن إهتمام المصارف المبحوثة بالخيار الاستراتيجي للتسويق بمقدار وحدة واحدة سيؤدي إلى زيادة الاداء التسويقي بمقدار (0.454)، وبلغت قيمة معامل التحديد (R2) (0.592) مما يعني إن (59.2\%) من التباين الذي يحدث في الاداء التسويقي يفسره الخيار الاستراتيجي للتسويق، أما الباقي والبالغ (40.8\%) تفسره متغيرات أخرى لم

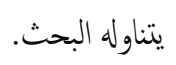

أ. يوّجد تاثير مَعنوي للتخطيط الاستراتيجي للتسويق مجتمعة في الأداء التسويقي مجتمعة: وجود تأثير معنوي موجب للتخطيط الاستراتيجي التسويقي مجتمعة في الاداء التسويقي مجتمعة، إذ بلغت قيمة F المحسوبة (40.715) وهي أكبر من قيمها الجدولية والبالغة (4.001)، كما إن مستوى المعنوية المحسوبة والبالغة (0.000)كانت أقل من مُستَوى المعنوية المستخدمة للبحث والبالغة (0.05)،وعزز ذلك قيمة (B) والبالغة (0.611)، مما يعني إن مساهمة التخطيط الاستراتيجي للتسويق بمقدار وحدة واحدة ستؤدي الى لى زيادة الاداء التسويقي بمقدار (0.611)، وبلغت قيمة معامل التحديد (R) (0.376)،ما يعني إن (37.6\%) من النباين الذي يحدث في الاداء التسويقي يفسره التخطيط الاستراتيجي اللتسويق ، أما الباقي والبالغ (62.4\%) فتفسره متَغيرات اخرىى لم يتناوله البحث. وعليه تقبل فرضية الثأثير الرئيسة الثالثة.

$$
5 \text { الجدول }
$$

ثاثثير التخطيط الاستراتبجي للتسويق مجمعة في الأداء التسويقي كجمعة

\begin{tabular}{|c|c|c|c|c|c|}
\hline \multirow[b]{2}{*}{$\mathrm{Sig}$} & \multirow[b]{2}{*}{ F } & \multicolumn{3}{|c|}{ المتغير المعتمد / الأداء التسويقي } & \multirow{2}{*}{ المنغير المستقل } \\
\hline & & $\mathrm{F}$ & $\mathrm{R}^{2}$ & $\mathrm{~B}$ & \\
\hline & الجدولية الجية & المسوبة & & & الاستراتيجي \\
\hline 0.000 & 4.001 & 40.715 & 0.376 & 0.611 & للتسويق \\
\hline
\end{tabular}

spss المصدر: بالاعتماد على نتائج

ب. يُوجذْ ثَأثير مَعنوي موجب لابعاد التخطيط الاستراتيجي اللتسويق منفردة في الاداء التسويقي مجتمعة، الجدول (6).

$$
6 \text { الجدول } 6
$$

\begin{tabular}{|c|c|c|c|c|}
\hline \multicolumn{4}{|c|}{ المنغير المعمد / الأداء التسويقي للتسويق الأداء التسويقي مجمعة } & \multirow{2}{*}{ ابعاد التخطيط الاستراتيجي للتسويق } \\
\hline Sig & $\mathrm{T}$ & $\mathrm{R}^{2}$ & $\mathrm{~B}$ & \\
\hline 0.001 & 7.416 & 0.505 & 0.671 & الرسالة التسويقية \\
\hline 0.000 & 6.620 & 0.493 & 0.526 & الأهداف التسويقية \\
\hline 0.000 & 5.211 & 0.592 & 0.454 & الحيار الاستراتيجي للتسويق \\
\hline 0.000 & 6.531 & 0.311 & 0.462 & الخطة التسويقية \\
\hline 0.000 & 11.123 & 0.621 & 0.631 & الرقابة التسويقية \\
\hline
\end{tabular}

spss المصنَر: بالاعتماد على نتائم

وجود تَأثير مَعنوي موجَب للرسالة التسويقية في الاداء التسويقي مجتمعة، إذ بلغت قيمة (T5) المحسوبة (7.416) وهي أكبر من قيمتها الجدولية والبالغة 


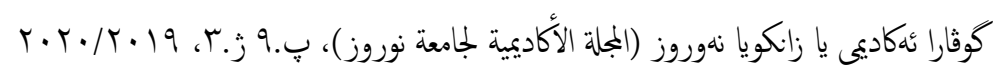

أشارت نتأُج البحث ومن خلال وصف الاداء التسويقي إهتمام المنظات المصارف المبحوثة بجميع عناصر الاداء التسويتي إذ تعالج إدارة المصرف أسباب عدم رضا الزبائن بأستمرار للحفاظ على حصتها السوقية وتوسيعها من خلال خفض أسعار خدماتها كوسيلة لتحقيق التميز في السوق. أظهرت نتائج التحليل وجود علاقة إرتباط معنوية موجبة بين ابعاد التخطيط الاستراتيجي للتسوبق مُجتَمعة ومنفردة والاداء التسويتي، مما يعني إن تَوفر التخطيط الاستراتيجي للتسويق مُجنمعة أو منفردة في المنظات المبحوثة سيحقق الاداء التسويقي.

أظهرت نتائُ التحليل وجود تأثير معنوي موجب لأبعاد التخطيط الاستراتيجي للتسويق مجتمعة ومنفَردة في الاداء التسويقي، مما يَنْي إن تَوَّر أبعاد التخطيط الاستراتيجي للتسويق مجتمعة أو منفردة في المنظلات المبحوثة

$$
\text { سيؤثر في تحقيق الاداء التسويقي. }
$$

2.6

ضرؤرة إستحضار أبعاد التخطيط الاستراتيجي اللتسويق في مجال عمل المنظمات المصرفية المبحوثة بالشكل الذي يغطي رسالة التسويقية، الاهداف التسويقية، الخيار الاستراتيجي، الخطة الاستراتيجية، الرقابة، لتأشير جاهزية المنظات المبحوثة لبلوغ أهدافها.

الاهنمام بالاداء التسويقي بشكل أكثر كأحد اسس نجاح المنظات المبحوثة، والاستفادة نها في مجال الميزة التنافسية لتحقيق أهداف المنظمة والزبائن على حد سواء. بعد أن أوضحت نتائُ إختبار تحليل الإتباط وجود علاقة إرتباط معنوية بين المتغيرات المُّستَلة والمتغير المعتمدة، توصي الباحثة بضرورة زيادة الاهتخام بالمتغيرات المعتمدة لكونها تساهم في تحقيق المتغير المُعتمد. بعد أن أوضحت نتائُ إختبار تحليل الانحدار وجود تأثير معنوي موجب للمتغيرات المستقلة في المتغير المعتمد، توصي الباحثة بضرورة إعتاد المنظلات المبحوثة إنموذج الدراسة الفرضي كالية عمل لتَحقيق الاداء

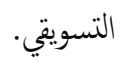

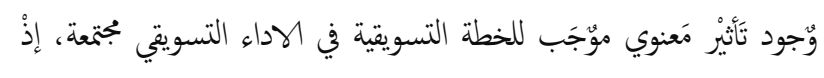
بلغت قيمة (T) المحسوبة (6.531) وهي أكَرَ من قيمها الجدولية والبالغة (2.0105)، كما إن مستوى المعنوية المحسوبة والبالغة (0.000)، كانت أقل من مستوى المعنوية المستخدمة للبحث والبالغة (0.05)، وعزَزَ ذَلك قُمَمة (B) والبَالغةَ (0.462)،مام يعني إن قيام المصارف برفع مستوى الخطة التسويقية بمقدَار وَحدة واحدة سَسيؤدي المى زيَّادة الاداء التسويقي بمقدار (0.462)، وَبَغتت قيمة معامل التحديد (R2) (0.311) مما يعني إن (31.1\%) من التباين الذي يحدث في الاداء التسويقي يفسره الخطة التسويقية، أما البَاقي وَالبالغ (68.9\%) تُقَسره متغيرات أخرى لم يتناوله البحث. وجود تأثير معنوي موجب للرقابة التسويقية في الاداء التسويقي مجتمعة، إذ بلغت قيمة (T) المَحسّوبة (11.123) وهي أكبر من قيمها الجدولية والبالغة (2.0105)، كما إن مستوى المعنوية المُّسوبة والبآلغة (0.000)، كانت أقل من مستوى المعنَوية المستخدمة للبحث والبالغًَ (0.05)، وعزَز ذلك قيمة (B) والبالغة (0.631)،مما يعني إن إهتمام المصارف بإجراءات الرقابة التسويقية بمقدار وَحدةَ واحُدة سيؤدي الى زيادَة الاداء التسويقي بمقدار (0.631)،

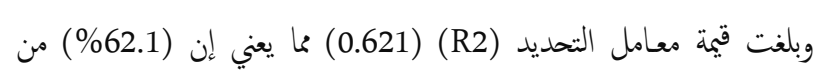
التباين الذي يحدث في الاداء التسويقي يفسره الحيار الاستراتيجي التسويقي، أما الباقي والبالغُ (37.9\%) تفسره متغيرات أخرى لم يتـاوله البحث.

6. المبحث الخامس: الاستناجات والمقترحات

1.6 الاستنثاجات

أشارت نتاجُج البحث ومن خلال وصف التخطيط الاستراتيجي للتسويق إهنام المنظات المبحوثة بجميع أبعاد التخطيط الاستراتيجي اللتسويق، من خلال إدراك أهمية وجود رسالة تسويقية تساعد في تنسيق القرارات المتخذة من خلال وضع إستراتيجية تسويقية تساهم في تحقيق الاهداف التسويقية التي تتناسب مع الانشطة الموضوعة في الموازنة المقدرة في الخطة إذ تنصب الرقابة على تشخيص مكان الخلل. 


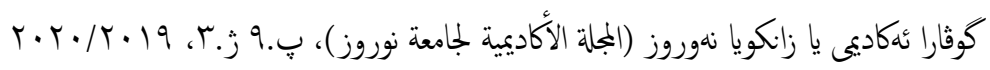

16. يجيى ، ندى فائز, (2012) ، العوامل المحدة التبني التجارة الكلكترونية و أثرها على الأداء

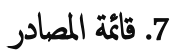

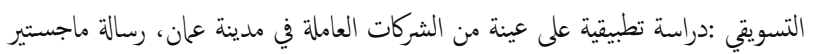

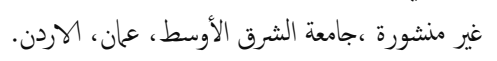

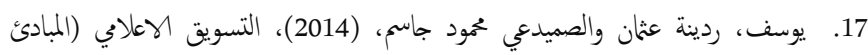

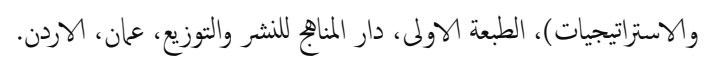

18. Donnelly, Jim \& Peter, J. Pual, (2007), Marketing management, $8^{\text {th }}$ Edition, , The McGraw-Hill Companies, Inc., New York, USA.

19. Kotler, Philip\& Keller, Kevin Lane, (2006), Marketing management, $12^{\text {th }}$ edition, person Education, Inc., New Jersey, USA.

20. Veresová, Eleonóra, (2002), Marketing Plan, Vol. X, 8, Narodna Banka Slovenska, Economics Focus, Slovenska.

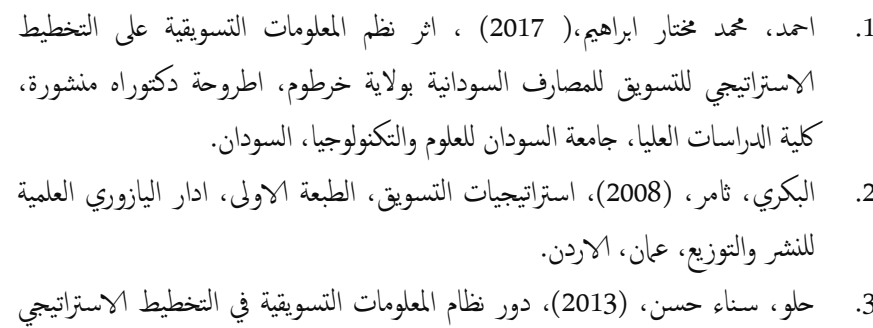

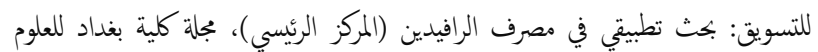
الاقتصادية، العدد الرابع والثلاثون، العراق.

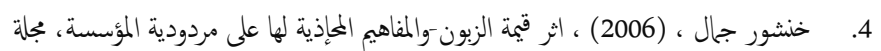

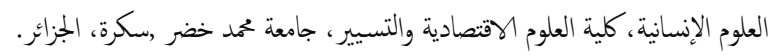
الذويب مولود علي موسى، (2015)، اثر التخيط الاستراتيحي التسويقي على اداء المنظلات : دراسة تطبيقية على شركات انتاج الدواء العاملة في ليبيا، رسالة ماسبجنير منشور، كلية الدراسات العليا، جامعة السودان للعلوم والتكنولوجيا، ليبيا. 6. الزيواني ، عواطف يونس إسهاعيل ، (2004) ، انعكاسات التجارة لالكترونية على لأداء

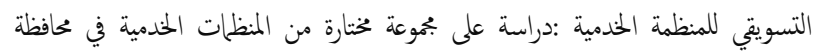
نينوى، أطروحة غير منشورة ،جامعة الموصل.

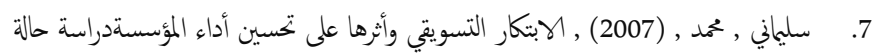
:مؤسسة ملبنة الحضنة بالمسيلة رسالة ماجستير منشورة , جامعة الجزائر.

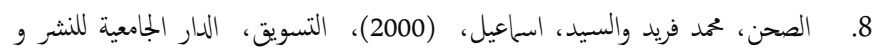
التوزيع، الإسكندرية، مصر.

9. الصيرفي، محد، (2005)، إدارة التسويق، مؤسسة حورس الدولية للنشر والتوزيع، الإسكندرية، مصر.

10. العوامرة، محمد عبدالله وزيادات، محمد عواد، (2012)، استراتيجيات التسويق: منظور متكمل، دار ومكتبة الحامد للنشر والتوزيع، عمان، الاردن.

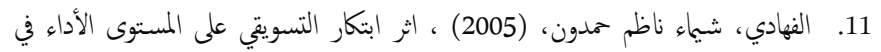

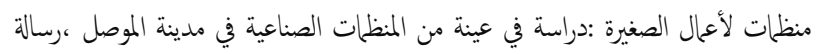
ماجستير غير منشورة ،جامعة الموصل. 12. مالك، زهير وعبيد، لطفي، (2017)، دور التخطيط الاستراتيجي اللتسويق تحسين اداء

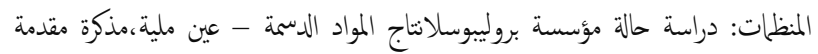

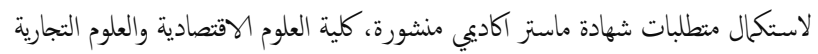
وعلوم التسيير، جامعة العربي التبسي - تبسة، الجزائر.

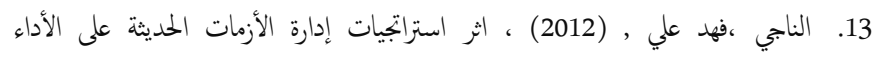

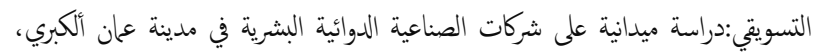

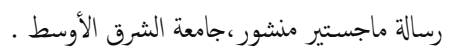

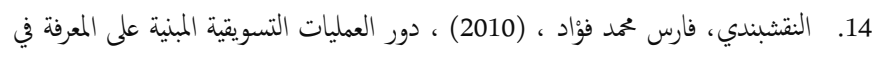

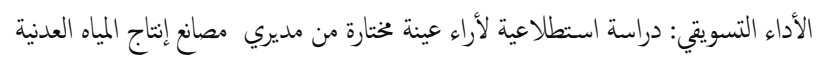
في أقليم كردستان - العراق ، رسالة ماجستير غير منشورة،جامعة دهوك.

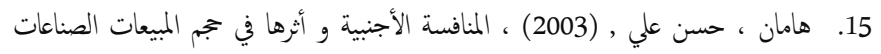

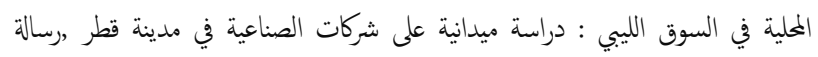
ماجستير منشورة، جامعة مصراته، ليبيا. 


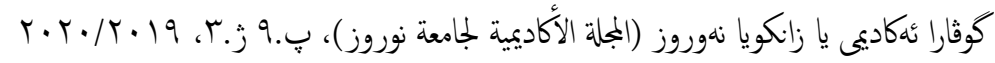




\section{م / استمارة استبانة}

البحــث الموسـوم (دور التخطـيط الاسـتراتيجي للتســويق في تعزيـز الأداء التسويقي /دراسـة اسـتطلاعية لاراء عينـة مـن المـوظفين في

عدد مـن مصارف مدينة دهوك، معـدة لغرض إجراء بحثث علمي ، لذا نرجو تعاونكم معنـا عن طريق اختيار الإجابة المناسـبة لخدمة البحث العلمي مع الشكر والتقدير ـ (متين كاره زانكو داسنيا خبات مالطا أولا : المعلومات العامة
أنثى ( )
ذ) ( )

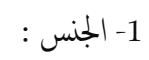

2- العمر: 25 سنة فأقل ( ) 25 - 35 سنة ()، 36 -46 سنة ( )، 47 سنة فاكثر ( )

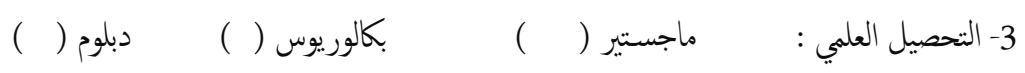

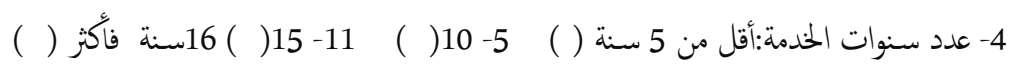
يرجى تأشير الإجابة بوضع علامة ( ل ل ) أمام الخيار الذي تراه منا سبا

\begin{tabular}{|c|c|c|c|c|c|c|}
\hline لاتاتفـــــق & 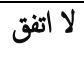 & محايد & اتفق & اتفـق بثــدة & \multirow{2}{*}{\multicolumn{2}{|c|}{ ثانيا: ابعاد التخطيط الاستراتيجي للتسويق }} \\
\hline بشدة 1 & 2 & 3 & 4 & 5 & & \\
\hline \multicolumn{7}{|c|}{ 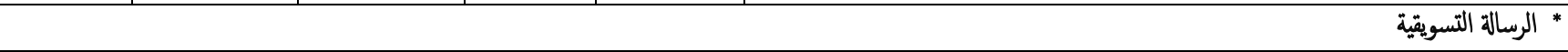 } \\
\hline & & & & & ادارة المصرف لها تصور واضح عن الانشطة التي تمارسها & 1 \\
\hline & & & & & تحرص ادارة المصرف على تعريف الزبائن بمختلف المدمات التي تقدما & 2 \\
\hline & & & & & يدرك الموظفون بالمصرف مضمون الرسالة التسويقية & 3 \\
\hline & & & & & 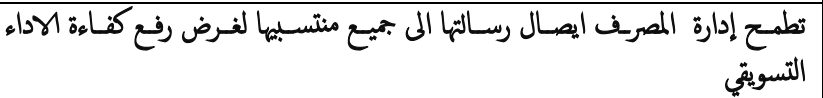 & 4 \\
\hline & & & & & تدرك ادارة المصرف أهمية وجود رسالة تسويقية لها. & 5 \\
\hline \multicolumn{7}{|c|}{ الاهداف التسويقية } \\
\hline & & & & & لدى ادارة المصرف اهداف طويلة الاجل تسعى الى تحقيقها & 6 \\
\hline & & & & & تتسم الاهداف التسويقية بالمرونة والقدرة على التكيف مع المتغيرات غير المثوقعة & 7 \\
\hline & & & & & يطور المصرف اهدافه التسويقية دوريا على وضع نتاجُ تحليلها المستمر. & 8 \\
\hline & & & & & تساعد الاهداف في تنسيق القرارات المتخذة بالمصرف & 9 \\
\hline \multicolumn{7}{|c|}{ * الخيار الاستراتيجي للتسويق } \\
\hline & & & & & ت تحدد ادارة المصرف القطاعات السوقية المستهدفة & 10 \\
\hline & & & & & تعمل إدارة المصرف على تحليل الفرص والتهيدات في البيية التسويقية & 11 \\
\hline & & & & & 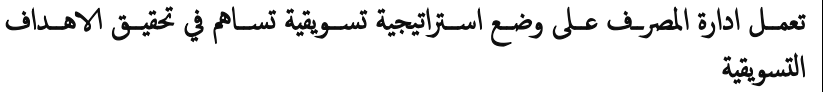 & 12 \\
\hline & & & & & تتضمن الاستراتيجية التسويقية لادارة للمصرف استراتيجيات المزيج التسويقي & 13 \\
\hline \multicolumn{7}{|c|}{ * * الخطة التسويقية } \\
\hline & & & & & تحرص إدارة المصرف على تنفيذ الانشطة التسويقية بما يططابق مع خطها & 14 \\
\hline & & & & & تثتاسب الانشطة الموضوعة مع الموازنة المقدرة في المُطة & 15 \\
\hline & & & & & تعمل الادارة العليا على تذليل العقبات التي تعترض تنفيذ المططة التسويقية & 16 \\
\hline & & & & & تهيئ إدارة المصرف الملاك لتنفيذ الحطة التسويقية في الوقت المناسب & 17 \\
\hline
\end{tabular}




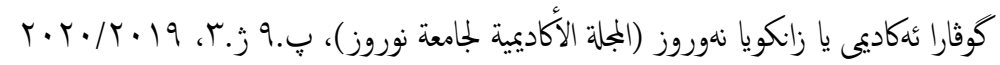

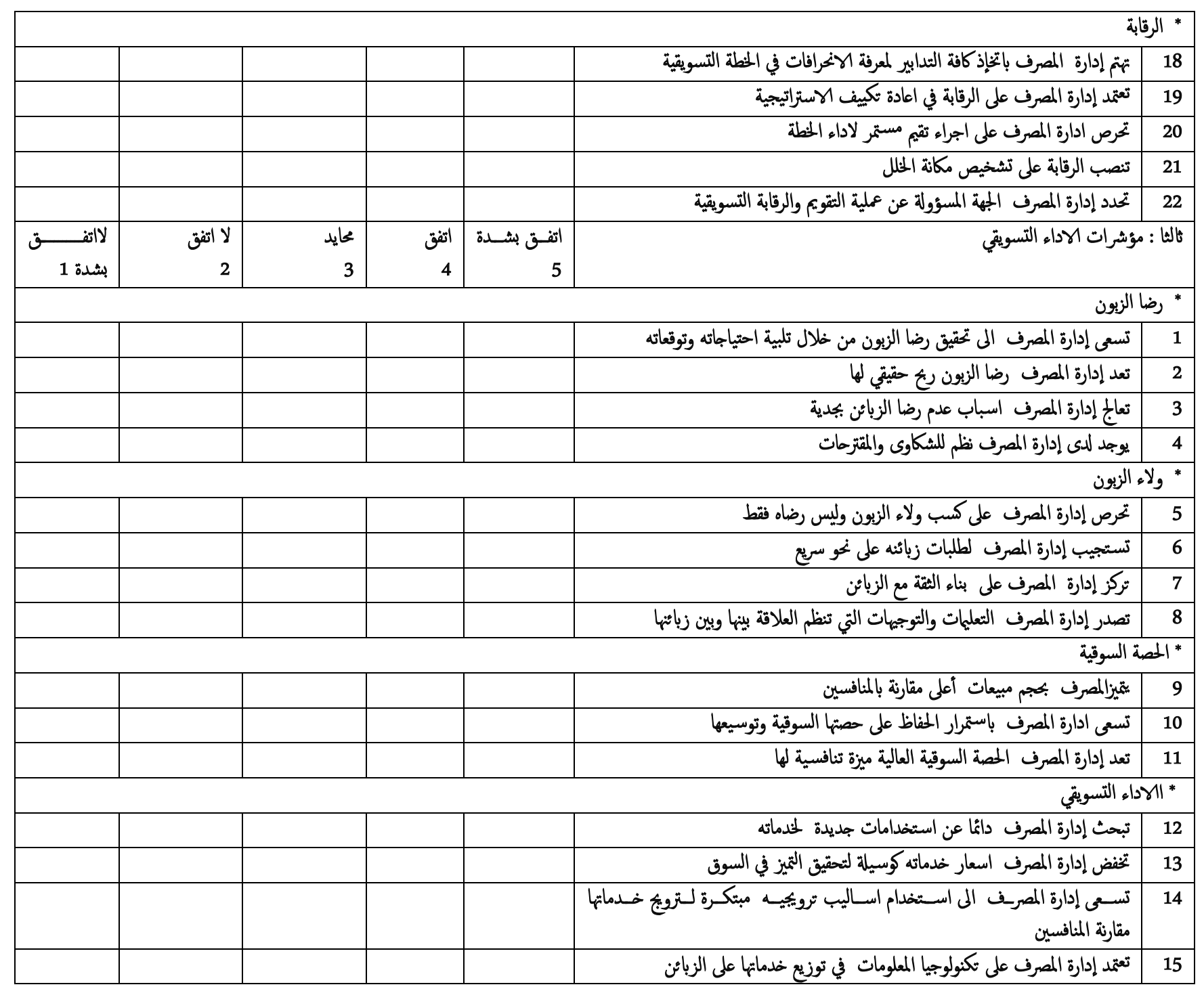

